\title{
Effects of nitrogen and potassium application rates on growth and yield of garlic (Allium sativum L.) planted in Ninh Thuan province
}

\author{
Nguyen H. Pham*, \& Thu D. Nguyen \\ Faculty of Agronomy, Nong Lam University, Ho Chi Minh City, Vietnam
}

ARTICLE INFO
Research Paper
Received: August 15, 2019
Revised: November 12, 2019
Accepted: December 25, 2019
Keywords
Garlic (Allium sativum L.)
Nitrogen
Potassium
Rates
Sandy soil
*Corresponding author
Pham Huu Nguyen
Email: phnguyen@hcmuaf.edu.vn

\begin{abstract}
The objectives of the study were to determine the optimum application rates of nitrogen and potassium for good growth, high yield and economic efficiency of garlic cultivated on the sandy soil of Ninh Thuan province in Winter-Spring season 2018 - 2019. The experiment was laid out in strip-plot design with three replications. Vertical-strip plot factor (A) was four application rates of nitrogen $\left(\mathrm{A}_{1}: 150 ; \mathrm{A}_{2}: 200 ; \mathrm{A}_{3}: 250\right.$, and $\left.\mathrm{A}_{4}: 300 \mathrm{~kg} \mathrm{~N} / \mathrm{ha}\right)$. Horizontal-strip plot factor $(\mathrm{B})$ was for three application rates of potassium $\left(\mathrm{B}_{1}\right.$ : 90; $\mathrm{B}_{2}: 120$, and $\left.\mathrm{B} 3: 150 \mathrm{~kg} \mathrm{~K}_{2} \mathrm{O} / \mathrm{ha}\right)$. The study results showed that the combined application of $200 \mathrm{~kg} \mathrm{~N} / \mathrm{ha}$ and $120 \mathrm{~kg} \mathrm{~K} \mathrm{~K}_{2} \mathrm{O} / \mathrm{ha}$ on the base of $80 \mathrm{~kg} \mathrm{P} 2 \mathrm{O} 5$ and 20 tons of cow manure resulted in higher plant height $(58.2 \mathrm{~cm})$, number of leaves (8.7 leaves/plant), the highest diameter of garlic bulb $(3.5 \mathrm{~cm})$, the highest average bulb weight $(15.8 \mathrm{~g} / \mathrm{bulb})$ with a total of 17.1 cloves/bulb, the high commercial garlic bulb yield (13.42 tons/ha), and the highest profit $(373,665,800 \mathrm{VND} / \mathrm{ha} / \mathrm{crop})$ with the profit margin was 2.15.
\end{abstract}

Cited as: Pham, N. H., \& Nguyen, T. D. (2020). Effects of nitrogen and potassium application rates on growth and yield of garlic (Allium sativum L.) planted in Ninh Thuan province. The Journal of Agriculture and Development 19(1), 41-48. 


\title{
Ảnh hưởng của các mức phân đạm và kali đến sinh trưởng và năng suất tỏi (Allium sativum L.) trồng tại tỉnh Ninh Thuận
}

\author{
Phạm Hưuu Nguyên* \& Nguyễn Đặng Thư \\ Khoa Nông học, Trường Đại học Nông Lâm TP.HCM, TP. Hồ Chí Minh
}

THÔNG TIN BÀI BÁO
Bài báo khoa học
Ngày nhận: 15/08/2019
Ngày chỉnh sưa: 12/11/2019
Ngày châp nhận: 25/12/2019
Từ khóa
Đạm
Đất cát
Kali
Liều lượng
Tỏi
*Tác giả liên hệ
Phạm Hữu Nguyên
Email: phnguyen@hcmuaf.edu.vn

\section{TÓM TẮT}

Mục tiêu của nghiên cứu nhằm xác định được liều lượng đạm và kali phù hợp cho cây tỏi trồng vụ Đông Xuân 2018 - 2019 trên nền đất cát tại tỉnh Ninh Thuận sinh trưởng mạnh, đạt năng suất và hiệu quả kinh tế cao. Thí nghiệm hai yếu tố được bố trí theo kiểu lô sọc (Strip-plot design) và 3 lần lặp lại; yếu tố sọc dọc $(\mathrm{A})$ gồm 4 liều lượng phân đạm $(\mathrm{kg} \mathrm{N} / \mathrm{ha}): \mathrm{A}_{1}: 150, \mathrm{~A}_{2}: 200, \mathrm{~A}_{3}: 250$ và $\mathrm{A}_{4}: 300$; yếu tố sọc ngang $(\mathrm{B})$ gồm 3 liều lượng kali $\left(\mathrm{kg} \mathrm{K}_{2} \mathrm{O} / \mathrm{ha}\right)$ : $\mathrm{B}_{1}$ : 90 , $\mathrm{B}_{2}: 120, \mathrm{~B}_{3}: 150$. Kết quả đã xác định được bón kết hợp $200 \mathrm{~kg} \mathrm{~N}$

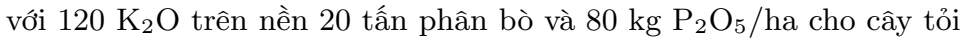
trồng trên đất cát tại Ninh Thuận có chiều cao cây đạt $58,2 \mathrm{~cm} /$ cây và 8,7 lá/cây ở 75 ngày sau trồng; khối lượng củ nặng nhất đạt 15,8 $\mathrm{g} / \mathrm{củ}$, có 17,1 tép/củ; giúp cây tỏi đạt năng suất thương phẩm là 13,42 tấn/ha; đường kính củ tỏi lớn nhất $(3,5 \mathrm{~cm})$, có 17,1 tép/củ, có $45,5 \%$ củ loại 1 , đạt $53,8 \%$ củ loại 2 và củ 1 tép là $0,7 \%$; đạt lợi nhuận 373.665.800 đồng/ha/vụ và tỷ suất lợi nhuận cao nhất là 2,15 .

\section{1. Đặt Vấn Đề}

Cây tỏi (Allium sativum L.) là cây gia vị có giá trị kinh tế và là một loại dược liệu quý được trồng phổ biến tại tỉnh Ninh Thuận. Năm 2016, diện tích trồng tỏi tại huyện Ninh Hải là 62 ha chiếm 46,3\% diện tích trồng tỏi cả tỉnh Ninh Thuận (NTSD, 2017). Để cây tỏi có năng suất cao và chất lượng tốt ngoài giống, kỹ thuật trồng và chăm sóc thì bón phân hợp lí là việc rất quan trọng. Theo Nguyen \& ctv. (2011), để bón phân hợp lý cần xác định được lượng phân bón thích hợp, tỷ lệ thích hợp giữa các loại phân bón, thời kỳ sử dụng và phương pháp thích hợp cho từng đối tượng cây trồng. Đối với cây tỏi, phân đạm và kali là nguồn dinh dưỡng quan trọng hàng đầu cho sự gia tăng năng suất. Theo Sebnie \& ctv. (2018), bón $92 \mathrm{~kg} \mathrm{~N} /$ ha và $42 \mathrm{~kg} \mathrm{P}_{2} \mathrm{O}_{5}$ /ha giúp gia tăng năng suất tỏi $48,3 \%$ so với đối chứng không bón phân đạm và lân. Cây tỏi đã hấp thu lượng dinh dưỡng $(\mathrm{kg} / \mathrm{ha})$ là $201-244 \mathrm{~N}, 28$ - 36
P, $106-127 \mathrm{~K}, 17-32 \mathrm{Ca}, 5-7 \mathrm{Mg}, 49-64 \mathrm{~S}$, $0,7-1,6 \mathrm{Na}$ và $0,11-0,16 \mathrm{Mn}$ (Minard, 1978). Theo Nguyen (2012), công thức phân phù hợp nhất cho cây tỏi trồng tại Văn Hải, Phan Rang - Tháp Chàm cho một ha là 3 tấn phân hữu cơ sinh học Trichoderma, $1.000 \mathrm{~kg}$ vôi, $168 \mathrm{~kg} \mathrm{~N}$ $80 \mathrm{~kg} \mathrm{P}_{2} \mathrm{O}_{5}-150 \mathrm{~kg} \mathrm{~K} \mathrm{~K}_{2} \mathrm{O}$. Trong khi đó, Tran (2015) đề nghị công thức phân bón phù hợp là 20 tân phân chuồng ủ hoai, $1.000 \mathrm{~kg}$ vôi, $200 \mathrm{~kg}$ $\mathrm{N}-80 \mathrm{~kg} \mathrm{P} \mathrm{P}_{2} \mathrm{O}_{5}-120 \mathrm{~kg} \mathrm{~K} \mathrm{~K}_{2} \mathrm{O}$ kết hợp với $60 \mathrm{~kg}$ $\mathrm{S}$ cho cây tỏi trồng tại xã Thanh Hải nhưng tại xã Vĩnh Hải, Ninh Hải, Ninh Thuận chỉ cần bón kết hợp $40 \mathrm{~kg} \mathrm{~S} /$ ha. Theo điều tra nhanh năm 2018, năm hộ trồng tỏi tại nơi thí nghiệm đã bón lượng phân cho một ha tỏi là $160-180 \mathrm{~kg} \mathrm{~N}$, $80 \mathrm{~kg} \mathrm{P}_{2} \mathrm{O}_{5}$ và $90-120 \mathrm{~kg} \mathrm{~K} \mathrm{~K}_{2} \mathrm{O}$. Như vậy, mỗi vùng đất khác nhau thì việc khuyến cáo sử dụng lượng phân bón khác nhau. Vì vậy, nghiên cứu này nhằm xác định được liều lượng phân đạm và kali phù hợp cho cây tỏi sinh trưởng mạnh, đạt năng suất và hiệu quả kinh tế cao khi trồng trền 
vùng đất cát pha tại Ninh Hải, Ninh Thuận.

\section{Vật Liệu và Phương Pháp Nghiên Cứu}

\subsection{Thời gian và địa điểm nghiên cứu}

Nghiên cứu đã được thực hiện từ tháng 10/2018 - 03/2019 tại Mỹ Tường 1, Nhơn Hải, Ninh Hải, Ninh Thuận.

\section{2. Điều kiện thí nghiệm}

Đất đai: Đất cát có sa cấu nhẹ $(97,20 \%$ cát, $1,91 \%$ thịt và $0,89 \%$ sét), đất kiềm có $\mathrm{pH}_{\mathrm{H}_{2} \mathrm{O}}$ là 7,16 ; rất nghèo dinh dưỡng $(0,04 \% \mathrm{~N} ; 0,13 \% \mathrm{P}$; $0,56 \mathrm{mg} / 100 \mathrm{~g} \mathrm{~N}-\mathrm{NH}_{4}^{+}$và $41,69 \mathrm{mg} / 100 \mathrm{~g} \mathrm{P}_{2} \mathrm{O}_{5}$; và $0,74 \%$ chất hữu cơ); đất chuyên canh hành, tỏi.

Thời tiết: Nhiệt độ trung bình của các tháng dao động từ $25,2^{\circ} \mathrm{C}-29,5^{\circ} \mathrm{C}$, từ tháng 1 trở đi, số giờ nắng trên 7 giờ/ngày thích hợp quá trình hình thành củ. Ẩm độ không khí trung bình từ $71 \%-83 \%$.

Giống: Giống tỏi trắng địa phương có lá xanh đậm to bản, thời gian sinh trưởng từ 120 - 135 ngày; củ non màu phớt tía, củ già to đường kính $3,0-4,5 \mathrm{~cm}$ và chắc. Trồng 1 tép tỏi/hốc với khoảng cách giữa các hốc $10 \mathrm{~cm} \times 10 \mathrm{~cm}$ (1.000.000 cây/ha).

\subsection{Bố trí thí nghiệm}

Thí nghiệm hai yếu tố được bố trí theo kiểu lô sọc (Strip - plot Design), 3 lần lặp lại, 12 nghiệm thức (Gomez \& Gomez, 1984). Yếu tố sọc dọc (A), lượng phân đạm (kg N/ha): $\mathrm{A}^{1}: 150$ (ĐC), $\mathrm{A}_{2}: 200 ; \mathrm{A}_{3}$ : 250 và $\mathrm{A}_{4}$ : 300 ; Yếu tố sọc ngang (B), lượng phân kali $\left(\mathrm{kg} \mathrm{K} \mathrm{K}_{2} \mathrm{O} / \mathrm{ha}\right)$ : $\mathrm{B}_{1}: 90 ; \mathrm{B}_{2}$ : 120 (ĐC) và $\mathrm{B} 3: 150$. Tồng số có 36 ô thí nghiệm với diện tích là $4 \mathrm{~m}^{2} / \mathrm{o}$ (Bảng 1 ).

\subsection{Thu thập số liệu}

Lúc 75 ngày sau trồng (NST), chọn 5 điểm theo đường chéo góc/ô thí nghiệm với 2 cây/điểm, không chọn cây ngoài đầu hàng để đo chiều cao cây và đếm số lá. Thời điểm $135 \mathrm{NST}$, thu hoạch 10 cây/điểm với 5 điểm/ô theo đường chéo góc (50 củ/ô/lần lặp lại) đem phơi dưới mái che 15 ngày rồi cân khối lượng củ, tính năng suất lý thuyết và thương phẩm (tấn/ha), đo đường kính củ, đếm số tép/củ; phân loại và tính tỷ lệ \% củ loại 1 (củ to chắc, trắng, đường kính $\geq 3 \mathrm{~cm}$ ), củ loại 2 (củ hơi trắng, đường kính $1,5-3,0 \mathrm{~cm}$ ) và củ tỏi đặc biệt chỉ có một tép tỏi. Tính tổng chi, tổng thu, lợi nhuận (đồng/ha/vụ) và tỉ suất lợi nhuận.

\subsubsection{Xử lý số liệu}

Số liệu được tính toán bằng phần mềm Microsoft Excel. Phân tích ANOVA, trắc nghiệm phân hạng LSD với độ tin cậy $\alpha=0,05$ và $\alpha=$ 0,01 bằng phần mềm SAS 9.1 bản Portable.

\section{Kết Quả và Thảo Luận}

\section{1. Ảnh hưởng của 4 mức phân đạm và 3 mức kali đến sinh trưởng của cây tỏi}

Bảng 2 cho thấy rằng chiều cao cây tỏi khi bón $200 \mathrm{~kg}$ N/ha đạt $56,7 \mathrm{~cm} /$ cây khác biệt không có ý nghĩa so với bón $250 \mathrm{~kg} \mathrm{~N} / \mathrm{ha}(55,6 \mathrm{~cm} /$ cây) nhưng khác biệt rất có ý nghĩa so với bón 150 $\mathrm{kg} \mathrm{N} / \mathrm{ha}(53,1 \mathrm{~cm} /$ cây $)$ và $300 \mathrm{~kg} \mathrm{~N} / \mathrm{ha}(53,7$ $\mathrm{cm} /$ cây). Cây tỏi khi được bón $90 \mathrm{~K}_{2} \mathrm{O} /$ ha có chiều cao đạt $55,1 \mathrm{~cm} /$ cây khác biệt không có ý nghĩa so với bón $120 \mathrm{~K}_{2} \mathrm{O} / \mathrm{ha}$ (đối chứng) nhưng khác biệt có ý nghĩa khi bón $150 \mathrm{~kg} \mathrm{~K}_{2} \mathrm{O} / \mathrm{ha}$. Sự tương tác giữa 4 mức phân đạm và 3 mức phân kali đến chiều cao cây tỏi khác biệt không có ý nghĩa thống kê và biến thiên từ 53,2 - 58,6 cm/cây.

Bảng 2 cho thấy: khi bón 4 mức phân đạm đã có tác động làm thay đổi số lá và sự khác biệt có ý nghĩa thống kê. Khi bón 200 kg N/ha cây tỏi có 8,6 lá/cây khác biệt không có ý nghĩa so với bón $250 \mathrm{~kg} \mathrm{~N} /$ ha (8,5 lá/cây) nhưng khác biệt có ý nghĩa so với bón $150 \mathrm{~kg} \mathrm{~N} / \mathrm{ha}(\mathrm{DC})$ và $300 \mathrm{~kg}$ N/ha chỉ đạt 8,4 lá/cây. Số lá/cây tỏi khi được bón 90,120 và $150 \mathrm{~kg} \mathrm{~K}$ O/ha khác biệt không có ý nghĩa thống kê. Sự tương tác giữa 4 mức phân đạm và 3 mức phân kali đến số lá tỏi khác biệt không có ý nghĩa thống kê và dao động từ 8,1 8,7 lá/cây.

\section{2. Ảnh hưởng của bốn mức phân đạm và ba mức kali đến các yếu tố cấu thành năng suất và năng suất tỏi}

Bảng 3 cho thấy khối lượng trung bình 1 củ tỏi dao động khoảng 11,8 - 14,3 g/củ, khác biệt có ý nghĩa thống kê khi bón 4 mức phân đạm từ 150 - $300 \mathrm{~kg} \mathrm{~N} /$ ha. Khi bón $200 \mathrm{~kg} \mathrm{~N} /$ ha đã đạt 14,3 $\mathrm{g} /$ củ khác biệt có ý nghĩa so với bón $150 \mathrm{~kg} \mathrm{~N} / \mathrm{ha}$ $(11,8 \mathrm{~g} / \mathrm{củ}), 250 \mathrm{~kg} \mathrm{~N} / \mathrm{ha}(12,3 \mathrm{~g} / \mathrm{củ})$ và $300 \mathrm{~kg}$ 
Bảng 1. Tỷ lệ (\%), số lần bón thúc phân đạm và phân kali

\begin{tabular}{cccc}
\hline \multirow{2}{*}{ Lần bón } & \multirow{2}{*}{ Ngày sau trồng (NST) } & \multicolumn{2}{c}{ Tỷ lệ (\%) } \\
\cline { 3 - 4 } & & Phân đạm & Phân kali \\
\hline 1 & 14 & 15 & 5 \\
2 & 28 & 15 & 5 \\
3 & 42 & 15 & 10 \\
4 & 56 & 30 & 40 \\
5 & 70 & 25 & 40 \\
\hline
\end{tabular}

Bảng 2. Ảnh hưởng của 4 mức phân đạm và 3 mức kali đến chiều cao, số lá của cây tỏi thời điểm 75 ngày sau trồng

\begin{tabular}{cccccc}
\hline \multirow{2}{*}{ Chỉ tiêu } & Phân đạm & \multicolumn{3}{c}{ Phân kali $\left(\mathrm{kg} \mathrm{K}_{2} \mathrm{O} / \mathrm{ha}\right)(\mathrm{B})$} & \multirow{2}{*}{ TB A } \\
\cline { 2 - 5 } & (kg N/ha) $(\mathrm{A})$ & 90 & $120(\mathrm{DC})$ & 150 & \\
\hline \multirow{4}{*}{ Chiều cao } & $150(\mathrm{DC})$ & 53,4 & 53,6 & 52,3 & $53,1^{\mathrm{c}}$ \\
(cm/cây) & 200 & 56,6 & 58,6 & 54,9 & $56,7^{\mathrm{a}}$ \\
& 250 & 56,6 & 55,4 & 54,8 & $55,6^{\mathrm{ab}}$ \\
& 300 & 53,9 & 54,0 & 53,2 & $53,7^{\mathrm{bc}}$ \\
\cline { 2 - 5 } & TB B & $55,1^{\mathrm{a}}$ & $55,4^{\mathrm{a}}$ & $53,9^{\mathrm{b}}$ & \\
\hline \multirow{4}{*}{ Số lá } & $\mathrm{CV}(\%)=3,5$ & $\mathrm{~F}_{\mathrm{A}}=15,3^{* *}$ & $\mathrm{~F}_{\mathrm{B}}=7,3^{*}$ & $\mathrm{~F}_{\mathrm{AxB}}=0,5^{\mathrm{ns}}$ & \\
(lá/cây) & $150(\mathrm{DC})$ & 8,4 & 8,3 & 8,3 & $8,4^{\mathrm{b}}$ \\
& 200 & 8,7 & 8,7 & 8,3 & $8,6^{\mathrm{a}}$ \\
& 250 & 8,4 & 8,4 & 8,4 & $8,5^{\mathrm{ab}}$ \\
& 300 & 8,1 & 8,4 & 8,4 & $8,4^{\mathrm{b}}$ \\
\hline & TB B & 8,4 & 8,5 & 8,4 & \\
\hline
\end{tabular}

a-c Trong cùng một nhóm giá trị trung bình, các số có cùng một ký tự theo sau khác biệt không có ý nghĩa thống kê; NS: Khác biệt không có ý nghĩa thống kê $(P>0,05)$, *: Khác biệt có ý nghĩa thống kê $(0,01<P \leq 0,05)$, **: Khác biệt rất có ý nghĩa thống kê $(P \leq 0,01)$.

Bảng 3. Ảnh hưởng của 4 mức phân đạm và 3 mức kali đến khối lượng 1 củ tỏi (g/củ)

\begin{tabular}{ccccc}
\hline \multirow{2}{*}{ Phân đạm (kg N/ha) $(\mathrm{A})$} & \multicolumn{3}{c}{ Phân kali $\left(\mathrm{kg} \mathrm{K} \mathrm{K}_{2} \mathrm{O} / \mathrm{ha}\right)(\mathrm{B})$} & \multirow{2}{*}{ TB A } \\
\cline { 2 - 4 } & 90 & $120(\mathrm{DC})$ & 150 & \\
\hline $150(\mathrm{DC})$ & $10,9^{\mathrm{d}}$ & $13,5^{\mathrm{bc}}$ & $11,0^{\mathrm{d}}$ & $11,8^{\mathrm{b}}$ \\
200 & $11,7^{\mathrm{cd}}$ & $15,8^{\mathrm{a}}$ & $15,5^{\mathrm{ab}}$ & $14,3^{\mathrm{a}}$ \\
250 & $12,2^{\mathrm{cd}}$ & $13,5^{\mathrm{bc}}$ & $11,3^{\mathrm{d}}$ & $12,3^{\mathrm{b}}$ \\
300 & $12,3^{\mathrm{cd}}$ & $12,2^{\mathrm{cd}}$ & $11,4^{\mathrm{cd}}$ & $12,0^{\mathrm{b}}$ \\
\hline TB B & $11,8^{\mathrm{B}}$ & $13,8^{\mathrm{a}}$ & $12,3^{\mathrm{b}}$ & \\
CV $(\%)=6,2$ & $\mathrm{~F}_{\mathrm{A}}=13,2^{*}$ & $\mathrm{~F}_{\mathrm{B}}=11,7^{*}$ & $\mathrm{~F}_{\mathrm{AxB}}=7,5^{* *}$ & \\
\hline
\end{tabular}

a-d Trong cùng một nhóm giá trị trung bình, các số có cùng một ký tự theo sau khác biệt không có ý nghĩa thống kê;*: Khác biệt có ý nghĩa thống kê $(0,01<P \leq 0,05)$, **: Khác biệt rất có ý nghĩa thống kê $(P \leq 0,01)$.

N/ha (12,0 g/củ); khối lượng trung bình củ đều thấp hơn các kết quả ghi nhận của Tran (2015) khi bón cùng lượng phân đạm $150 \mathrm{~kg} \mathrm{~N} / \mathrm{ha} 200 \mathrm{~kg}$ $\mathrm{N} /$ ha và $250 \mathrm{~kg} \mathrm{~N} /$ ha với số liệu lần lượt là 24,00 $\mathrm{g} / \mathrm{củ}, 23,95 \mathrm{~g} / \mathrm{củ}$ và $21,51 \mathrm{~g} / \mathrm{củ}$. Sự tác động của ba mức phân kali đến khối lượng trung bình củ khác biệt có ý nghĩa thống kê và dao động từ 11,8 - 13,8 g/củ; Trong đó, khi bón 120 kg K ${ }_{2} \mathrm{O}$ /ha có khối lượng trung bình củ là nặng nhất $(13,8 \mathrm{~g} / \mathrm{củ})$ khác biệt có ý nghĩa so với bón $90 \mathrm{~kg} \mathrm{~K}_{2} \mathrm{O}$ /ha và
$150 \mathrm{~kg} \mathrm{~K} \mathrm{~K}_{2} \mathrm{O} / \mathrm{ha}(11,8 \mathrm{~g} / \mathrm{củ}$ và $12,3 \mathrm{~g} / \mathrm{củ})$, như vậy bón khoảng $120 \mathrm{~kg} \mathrm{~K} \mathrm{~K}_{2} \mathrm{O} /$ ha là phù hợp. Sự tương tác giữa 4 mức phân đạm với 3 mức phân kali đến khối lượng củ trung bình khác biệt rất có ý nghĩa và dao động từ 11,0 - 15,8 g/củ; Khi bón $200 \mathrm{~kg}$ $\mathrm{N} /$ ha kết hợp với $120 \mathrm{~kg} \mathrm{~K} \mathrm{O} /$ ha cho khối lượng củ nặng nhất là $15,8 \mathrm{~g} /$ củ khác biệt có ý nghĩa so bón kết hợp với $90 \mathrm{~kg} \mathrm{~K}_{2} \mathrm{O} / \mathrm{ha}(11,7 \mathrm{~g} / \mathrm{củ})$, nhưng khác biệt không có ý nghĩa khi bón kêt hợp với $150 \mathrm{~kg} \mathrm{~K}{ }_{2} \mathrm{O} / \mathrm{ha}(15,5 \mathrm{~g} / \mathrm{củ})$. 
Bảng 4. Ảnh hưởng của 4 mức phân đạm và 3 mức kali đến năng suất tỏi

\begin{tabular}{|c|c|c|c|c|c|}
\hline \multirow{2}{*}{$\begin{array}{c}\text { Năng suất } \\
\text { (tấn/ha) }\end{array}$} & \multirow{2}{*}{$\begin{array}{c}\text { Phân đạm } \\
(\mathrm{kg} N / \mathrm{ha})(\mathrm{A})\end{array}$} & \multicolumn{3}{|c|}{ Phân kali (kg $\left.\mathrm{K}_{2} \mathrm{O} / \mathrm{ha}\right)(\mathrm{B})$} & \multirow{2}{*}{ TB A } \\
\hline & & 90 & $120(\mathrm{DC})$ & 150 & \\
\hline \multirow{6}{*}{ Lí thuyết } & $150(\mathrm{DC})$ & $10,93^{\mathrm{d}}$ & $13,46^{\mathrm{bc}}$ & $11,00^{\mathrm{d}}$ & $11,80^{b}$ \\
\hline & 200 & $11,73^{\mathrm{cd}}$ & $15,87^{\mathrm{a}}$ & $15,46^{\mathrm{ab}}$ & $14,36^{\mathrm{a}}$ \\
\hline & 250 & $12,20^{\mathrm{cd}}$ & $13,50^{\mathrm{bc}}$ & $11,27^{\mathrm{d}}$ & $12,32^{\mathrm{b}}$ \\
\hline & 300 & $12,33^{\mathrm{cd}}$ & $12,20^{\mathrm{cd}}$ & $11,40^{\mathrm{cd}}$ & $11,98^{\mathrm{b}}$ \\
\hline & TB B & $11,80^{\mathrm{B}}$ & $13,76^{\mathrm{a}}$ & $12,28^{b}$ & \\
\hline & $\mathrm{CV}(\%)=6,2$ & $\mathrm{~F}_{\mathrm{A}}=13,2^{*}$ & $\mathrm{~F}_{\mathrm{B}}=11,7^{*}$ & $\mathrm{~F}_{\mathrm{AxB}}=7,5^{* *}$ & \\
\hline \multirow{6}{*}{ Thương phẩm } & $150(\mathrm{DC})$ & 9,67 & 11,33 & 9,75 & $10,25^{\mathrm{b}}$ \\
\hline & 200 & 10,50 & 13,42 & 11,50 & $11,80^{\mathrm{a}}$ \\
\hline & 250 & 11,00 & 11,67 & 10,00 & $10,89^{\mathrm{ab}}$ \\
\hline & 300 & 10,58 & 10,67 & 10,17 & $10,47^{\mathrm{b}}$ \\
\hline & TB B & $10,44^{\mathrm{b}}$ & $11,77^{\mathrm{a}}$ & $10,35^{b}$ & \\
\hline & $\mathrm{CV}(\%)=8,4$ & $\mathrm{~F}_{\mathrm{A}}=4,3^{*}$ & $\mathrm{~F}_{\mathrm{B}}=6,6^{*}$ & $\mathrm{~F}_{\mathrm{AxB}}=1,6^{\mathrm{ns}}$ & \\
\hline
\end{tabular}

a-d Trong cùng một nhóm giá trị trung bình, các số có cùng một ký tự theo sau khác biệt không có ý nghĩa thống kê; ns: Khác biệt không có ý nghĩa thống kê $(P>0,05)$, *: Khác biệt có ý nghĩa thống kê $(0,01<P \leq 0,05)$, **: Khác biệt rất có ý nghĩa thống kê $(P \leq 0,01)$.

Bảng 5. Ảnh hưởng của 4 mức phân đạm và 3 mức kali đến đường kính củ, số tép/củ và tỷ lệ \% tỏi các loại

\begin{tabular}{|c|c|c|c|c|c|}
\hline \multirow{2}{*}{ Chỉ tiêu } & \multirow{2}{*}{$\begin{array}{c}\text { Phân đạm } \\
(\mathrm{kg} N / \mathrm{ha})(\mathrm{A})\end{array}$} & \multicolumn{3}{|c|}{ Phân kali (kg $\left.\mathrm{K}_{2} \mathrm{O} / \mathrm{ha}\right)(\mathrm{B})$} & \multirow{2}{*}{ TB A } \\
\hline & & 90 & $120(\mathrm{DC})$ & 150 & \\
\hline \multirow{6}{*}{$\begin{array}{l}\text { Đường kính } \\
\text { củ }(\mathrm{cm})\end{array}$} & $150(\mathrm{DC})$ & 2,7 & 3,1 & 2,8 & 2,9 \\
\hline & 200 & 2,9 & 3,5 & 2,7 & 3,0 \\
\hline & 250 & 2,8 & 2,9 & 3,0 & 2,9 \\
\hline & 300 & 2,8 & 2,8 & 2,8 & 2,8 \\
\hline & TB B & $2,8 \mathrm{~B}$ & $3,1 \mathrm{~A}$ & $2,8 \mathrm{~B}$ & \\
\hline & $\mathrm{CV}(\%)=10,8$ & $\mathrm{~F}_{\mathrm{A}}=0,24^{\mathrm{ns}}$ & $\mathrm{F}_{\mathrm{B}}=6,7^{*}$ & $\mathrm{~F}^{\mathrm{AxB}}=1,1^{\mathrm{ns}}$ & \\
\hline \multirow{6}{*}{$\begin{array}{l}\text { Số tép } \\
\text { (tép/củ) }\end{array}$} & $150(\mathrm{DC})$ & 13,6 & 15,6 & 15,8 & $14,9^{\mathrm{b}}$ \\
\hline & 200 & 15,9 & 17,1 & 16,7 & $16,6^{\mathrm{a}}$ \\
\hline & 250 & 15,6 & 16,7 & 15,8 & $16,0^{\mathrm{ab}}$ \\
\hline & 300 & 14,8 & 15,5 & 15,1 & $15,1^{\mathrm{b}}$ \\
\hline & TB B & $14,9^{B}$ & $16,1^{A}$ & $15,9^{A}$ & \\
\hline & $\mathrm{CV}(\%)=5,8$ & $\mathrm{~F}_{\mathrm{A}}=5,1^{*}$ & $\mathrm{~F}_{\mathrm{B}}=7,8^{*}$ & $\mathrm{~F}_{\mathrm{AxB}}=0,9^{\mathrm{ns}}$ & \\
\hline \multirow{5}{*}{$\begin{array}{l}\text { Tỷ lệ (\%) } \\
\text { tỏi loại } 1\end{array}$} & $150(\mathrm{DC})$ & 51,7 & 53,8 & 61,6 & 55,7 \\
\hline & 200 & 57,1 & 45,5 & 52,3 & 51,6 \\
\hline & 250 & 54,5 & 50,6 & 49,0 & 51,4 \\
\hline & 300 & 52,1 & 56,3 & 50,3 & 52,9 \\
\hline & TB B & 53,9 & 51,6 & 53,3 & \\
\hline \multirow{5}{*}{$\begin{array}{l}\text { Tỷ lệ (\%) } \\
\text { củ một tép }\end{array}$} & $150(\mathrm{DC})$ & 2,7 & 0,7 & 1,0 & 1,5 \\
\hline & 200 & 1,8 & 0,7 & 0,8 & 1,1 \\
\hline & 250 & 1,1 & 1,4 & 0,9 & 1,1 \\
\hline & 300 & 1,6 & 0,5 & 0,5 & 0,9 \\
\hline & TB B & 1,8 & 0,9 & 0,8 & \\
\hline
\end{tabular}

Trong cùng một nhóm giá trị trung bình, các số có cùng một ký tự theo sau khác biệt không có ý nghĩa thống kê; ns: Khác biệt không có ý nghĩa thống kê $(P>0,05)$, * Khác biệt có ý nghĩa thống kê $(0,01<P \leq 0,05)$.

Bảng 4 cho thấy, năng suất tỏi lí thuyết khác biệt có ý nghĩa thống kê khi bón bốn mức phân đạm; Khi bón $200 \mathrm{~kg} \mathrm{~N} /$ ha đạt năng suất tỏi lí thuyết là 14,36 tấn/ha khác biệt có ý nghĩa so với bón $150 \mathrm{~kg} \mathrm{~N} / \mathrm{ha}(11,80$ tấn/ha), $250 \mathrm{~kg} \mathrm{~N} / \mathrm{ha}$ $(12,32$ tấn/ha) và $300 \mathrm{~kg} \mathrm{~N} / \mathrm{ha}(11,98$ tấn/ha). Năng suất lí thuyết đạt 13,76 tấn/ha khi bón $120 \mathrm{~kg} \mathrm{K2O} /$ ha khác biệt có ý nghĩa thống kê 
Bảng 6. Ảnh hưởng của 4 mức phân đạm và 3 mức kali đến hiệu quả kinh tế của cây tỏi

\begin{tabular}{|c|c|c|c|c|c|}
\hline \multirow{2}{*}{ Chỉ tiêu } & \multirow{2}{*}{$\begin{array}{c}\text { Phân đạm } \\
(\mathrm{kg} \mathrm{N} / \mathrm{ha})(\mathrm{A})\end{array}$} & \multicolumn{3}{|c|}{ Phân kali (kg K $\left.{ }_{2} \mathrm{O} / \mathrm{ha}\right)$ (B) } & \multirow{2}{*}{ TB A } \\
\hline & & 90 & $120(\mathrm{DC})$ & 150 & \\
\hline \multirow{5}{*}{$\begin{array}{c}\text { Tổng chi } \\
\text { (1.000 đồng/ha/vụ) }\end{array}$} & $150(\mathrm{DC})$ & $172.129,5$ & $173.149,5$ & 174.169 .5 & $173.149,5$ \\
\hline & 200 & $173.104,2$ & $174.124,2$ & $175.144,2$ & $174.124,2$ \\
\hline & 250 & $174.087,9$ & $175.107,9$ & $176.127,9$ & $175.107,0$ \\
\hline & 300 & $175.060,8$ & $176.080,8$ & $177.100,8$ & $176.080,8$ \\
\hline & TB B & $173.595,6$ & $174.615,6$ & $175.635,6$ & \\
\hline \multirow{5}{*}{$\begin{array}{c}\text { Tổng thu } \\
\text { (1.000 đồng/ha/vụ) }\end{array}$} & $150(\mathrm{DC})$ & $452.680,9$ & $482.360,9$ & $435.420,0$ & $456.820,6$ \\
\hline & 200 & $480.600,0$ & $547.790,0$ & $488.209,1$ & $505.533,0$ \\
\hline & 250 & $479.429,1$ & $505.870,9$ & 420.410 & $468.570,0$ \\
\hline & 300 & $468.850,9$ & $454.249,1$ & 420.350 & $447.816,7$ \\
\hline & TB B & $470.390,2$ & $497.567,7$ & $441.097,3$ & \\
\hline \multirow{5}{*}{$\begin{array}{c}\text { Lợi nhuận } \\
\text { (1.000 đồng/ha/vụ) }\end{array}$} & 150 (ĐC) & $280.551,4$ & $309.211,4$ & $261.250,5$ & $283.671,1$ \\
\hline & 200 & $307.495,8$ & $373.665,8$ & $313.064,9$ & $331.408,8$ \\
\hline & 250 & $305.341,2$ & $330.763,0$ & $244.282,1$ & $293.462,1$ \\
\hline & 300 & $293.790,1$ & $278.168,3$ & $243.249,2$ & $271.735,9$ \\
\hline & TB B & $296.794,6$ & $321.777,1$ & $265.686,7$ & \\
\hline \multirow{5}{*}{$\begin{array}{l}\text { Tỷ suất } \\
\text { lợi nhuận }\end{array}$} & $150(\mathrm{DC})$ & 1,63 & 1,79 & 1,50 & 1,64 \\
\hline & 200 & 1,78 & 2,15 & 1,79 & 1,90 \\
\hline & 250 & 1,75 & 1,89 & 1,39 & 1,68 \\
\hline & 300 & 1,68 & 1,58 & 1,37 & 1,54 \\
\hline & TB B & 1,71 & 1,85 & 1,51 & \\
\hline
\end{tabular}

Giá bán (đồng/kg): Tỏi loại 1: 50.000; Tỏi loại 2: 30.000; Tỏi 1 tép: 270.000 (Hình 2).

so với bón $90 \mathrm{~kg} \mathrm{~K}$ O/ha (11,80 tấn/ha) và 150 $\mathrm{kg} \mathrm{K}_{2} \mathrm{O} /$ ha $(12,28$ tấn/ha). Sự tương tác giữa 4 mức phân đạm và 3 mức kali đến năng suất tỏi lí thuyết khác biệt rất có ý nghĩa thống kê; cùng mức phân $120 \mathrm{~kg} \mathrm{~K} \mathrm{~K}_{2} \mathrm{O} / \mathrm{ha}$, khi bón $200 \mathrm{~kg} \mathrm{~N} / \mathrm{ha}$ đạt 15,87 tấn/ha khác biệt không có ý nghĩa so với bón $150 \mathrm{~kg} \mathrm{~N} /$ ha $(15,46$ tấn/ha) nhưng khác biệt rất có ý nghĩa thống kê so với bón kết hợp giữa các mức phân đạm và kali còn lại.

Bảng 4 cho thấy năng suất tỏi thương phẩm khi bón $200 \mathrm{~kg} \mathrm{~N} /$ ha đạt 11,80 tấn/ha khác biệt có ý nghĩa so với bón $150 \mathrm{~kg} \mathrm{~N} / \mathrm{ha}(10,25$ tấn/ha) và $300 \mathrm{~kg} \mathrm{~N} / \mathrm{ha}(10,47$ tấn/ha), nhưng khác biệt không có ý nghĩa so với bón $250 \mathrm{~kg}$ N/ha $(10,89$ tấn/ha). Năng suất tỏi thương phẩm khi bón 120 kg K2O/ha (đối chứng) đạt 11,77 tấn/ha khác biệt có ý nghĩa so với năng suất thương phẩm khi bón $90 \mathrm{~kg} \mathrm{~K}{ }_{2} \mathrm{O} / \mathrm{ha}(10,43$ tấn/ha) và $150 \mathrm{~kg}$ $\mathrm{K} 2 \mathrm{O} / \mathrm{ha}$ (10,35 tấn/ha); Sự tương tác giữa 4 mức phân đạm và 3 mức phân kali đến năng suất tỏi thương phẩm dao động từ 9,67 - 13,42 tấn/ha và khác biệt không có ý nghĩa thống kê. Kết quả này có cao hơn so với báo cáo của Nguyen (2012) cây tỏi chỉ đạt năng suất thực thu cao nhất là 9,63 tấn/ha khi bón kết hợp $168 \mathrm{~kg} \mathrm{~N}$ và $120 \mathrm{~kg}$ $\mathrm{K}_{2} \mathrm{O} /$ ha trên nền đất cát tại phường Văn Hải,
Thành phố Phan Rang - Tháp Chàm.

3.3. Ảnh hưởng của bốn mức phân đạm và ba mức kali đến đường kính, số tép/củ và tỷ lệ củ tỏi các loại

Bảng 5 cho thấy rằng đường kính củ tỏi khi được bón 4 mức phân đạm khác biệt không có ý nghĩa thống kê và dao động từ $2,8-3,0 \mathrm{~cm}$. Đường kính củ tỏi khi bón $120 \mathrm{~kg} \mathrm{~K} /$ ha đạt 3,1 cm khác biệt có ý nghĩa thống kê so với đường kính củ khi bón $90 \mathrm{~kg} \mathrm{~K}_{2} \mathrm{O} / \mathrm{ha}(2,8 \mathrm{~cm})$ và 150 $\mathrm{kg} \mathrm{K} \mathrm{K}_{2} \mathrm{O} / \mathrm{ha}(2,8 \mathrm{~cm})$. Tương tác giữa 4 mức phân đạm với 3 mức phân kali đến đường kính củ tỏi khác biệt không có ý nghĩa thống kê và biến động từ 2,7 - 3,5 cm (Hình 1)

Kết quả Bảng 5 cho biết rằng số tép/củ khi bón $200 \mathrm{~kg}$ N/ha là 16,6 tép/củ khác biệt có ý nghĩa thống kê so với bón $150 \mathrm{~kg} \mathrm{~N} /$ ha (14,9 tép/củ) và $300 \mathrm{~kg} \mathrm{~N} / \mathrm{ha}(15,1 \mathrm{tép} / \mathrm{củ})$ nhưng khác biệt không có ý nghĩa với số tép/củ khi bón $250 \mathrm{~kg}$ $\mathrm{N} /$ ha (16,0 tép/củ). Số tép/củ ở 3 mức phân kali khác biệt có ý nghĩa thống kê, số tép/củ khi bón $120 \mathrm{~kg} \mathrm{~K} \mathrm{~K}_{2} \mathrm{O} / \mathrm{ha}$ (đối chứng) và $150 \mathrm{~kg} \mathrm{~K} \mathrm{~K}_{2} \mathrm{O} / \mathrm{ha}$ khác biệt không có ý nghĩa thống kê với số liệu lần lượt là 16,1 tép/củ và 15,9 tép/củ nhưng khác 


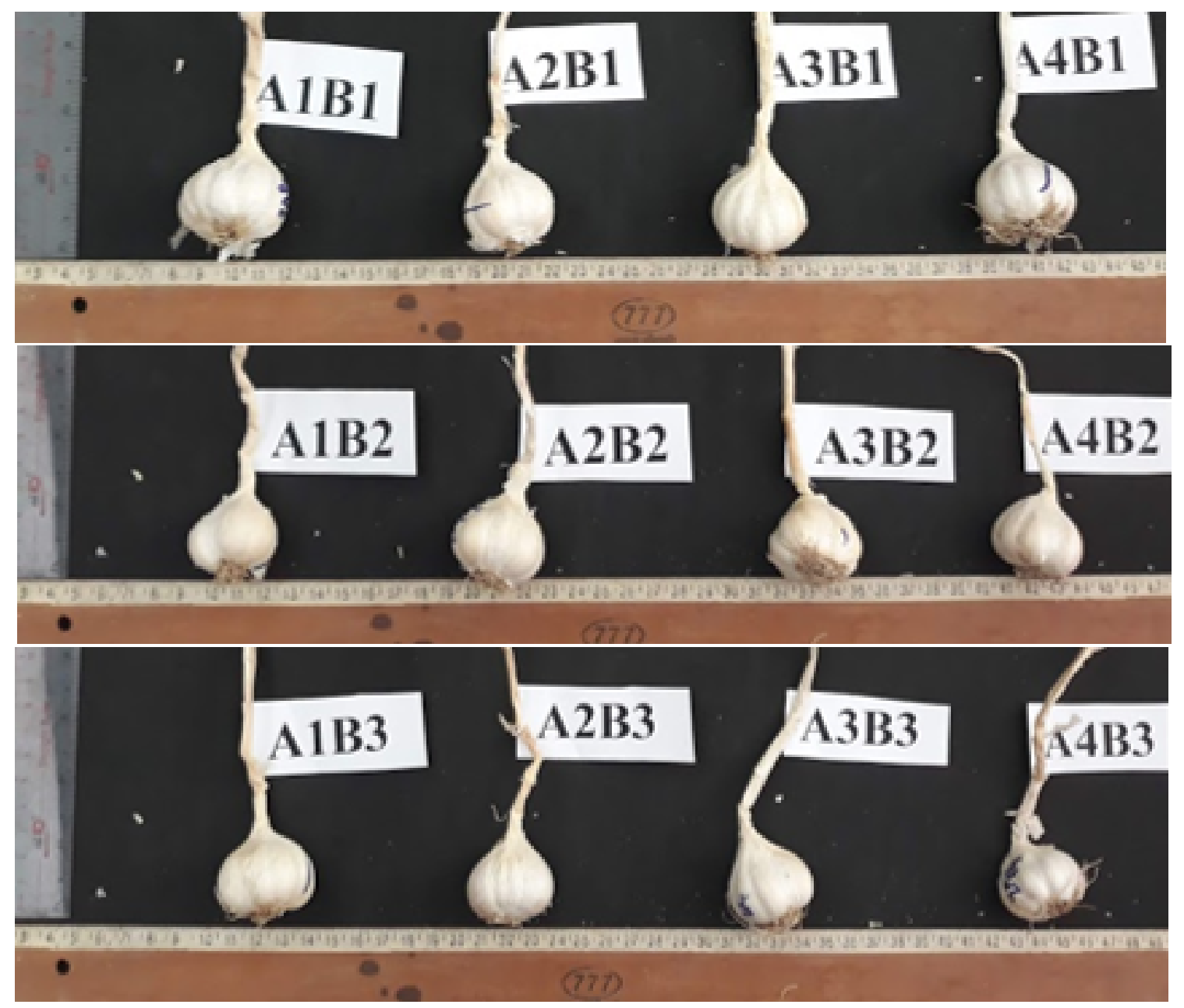

Hình 1. Củ tỏi ở các mức phân đạm $150\left(\mathrm{~A}_{1}\right), 200\left(\mathrm{~A}_{2}\right), 250\left(\mathrm{~A}_{3}\right), 300 \mathrm{~kg} \mathrm{~N} / \mathrm{ha}\left(\mathrm{A}_{4}\right)$ kết hợp với 90 (B $\left.\mathrm{B}_{1}\right)$, $120\left(\mathrm{~B}_{2}\right)$ và $150 \mathrm{~kg} \mathrm{~K} 2 \mathrm{O} / \mathrm{ha}\left(\mathrm{B}_{3}\right)$.

biệt có ý nghĩa thống kê so với bón $90 \mathrm{~kg} \mathrm{~K} \mathrm{~K}_{2} \mathrm{O} / \mathrm{ha}$ (14,9 tép/củ). Sự tương tác giữa 4 mức phân đạm và 3 mức phân kali đến số tép/củ khác biệt không có ý nghĩa thống kê và dao động từ 13,6 - 17,1 tép/củ.

Bón bốn mức đạm giúp cây tỏi có tỷ lệ củ tỏi loại 1 biến động từ $51,4 \%$ - 55,7\% (Bảng 5 ), trong khi đó bón ba mức phân kali có tỷ lệ tỏi loại 1 từ $51,6 \%-53,9 \%$. Bón $\left(150 \mathrm{~kg} \mathrm{~N}+150 \mathrm{~kg} \mathrm{~K} \mathrm{~K}_{2} \mathrm{O}\right) / \mathrm{ha}$ giúp tỷ lệ củ tỏi loại 1 cao nhất là $61,6 \%$ và tỷ lệ củ loại 2 là thấp nhất $(37,5 \%)$, trong khi bón $(200$ $\mathrm{kg} \mathrm{N}+120 \mathrm{~kg} \mathrm{~K} 2 \mathrm{O}$ )/ha giúp tỷ lệ củ tỏi loại 1 đạt $45,5 \%$ và tỷ lệ củ loại 2 là cao nhất $(53,8 \%)$. Tỏi một tép là củ không đẻ nhánh, củ nhỏ là loại tỏi trước kia không bán được và chỉ được nông dân sử dụng trong gia đình mà nguyên nhân có thể do thiếu phân bón, thời tiết không thuận lợi nhưng hiện nay tỏi một tép có giá bán rất cao vì rất hiếm, tỷ lệ củ tỏi một tép trong quá trình thí nghiệm rất thấp chỉ từ $0,5 \%$ đến $2,7 \%$; Tuy nhiên, nếu trồng tỏi có tỷ lệ tỏi một tép quá cao thì tổng lợi nhuận thường sẽ thấp; Khi bón các mức phân đạm 150, 200, 250 và $300 \mathrm{~kg} \mathrm{~N} /$ ha cho tỷ lệ tỏi 1 tép biến động không nhiều và dao động trong khoảng 0,9\% (bón $300 \mathrm{~kg} \mathrm{~N} /$ ha) dến 1,5\% (bón $150 \mathrm{~kg} \mathrm{~N} / \mathrm{ha}$ ). Bón kali ít $\left(90 \mathrm{~kg} \mathrm{~K} \mathrm{~K}_{2} \mathrm{O} / \mathrm{ha}\right.$ ) có tỷ lệ củ một tép cao hơn bón 120 hoặc $150 \mathrm{~kg}$ $\mathrm{K}_{2} \mathrm{O} /$ ha chứng tỏ phân kali có ảnh hưởng đến tỷ lệ củ tỏi một tép. Bón lượng phân thấp nhất (150 kg N kết hợp với $90 \mathrm{~kg} \mathrm{~K} \mathrm{~K}_{2} \mathrm{O} / \mathrm{ha}$ ) cây tỏi có tỷ lệ tỏi một tép cao nhất là $2,7 \%$. 

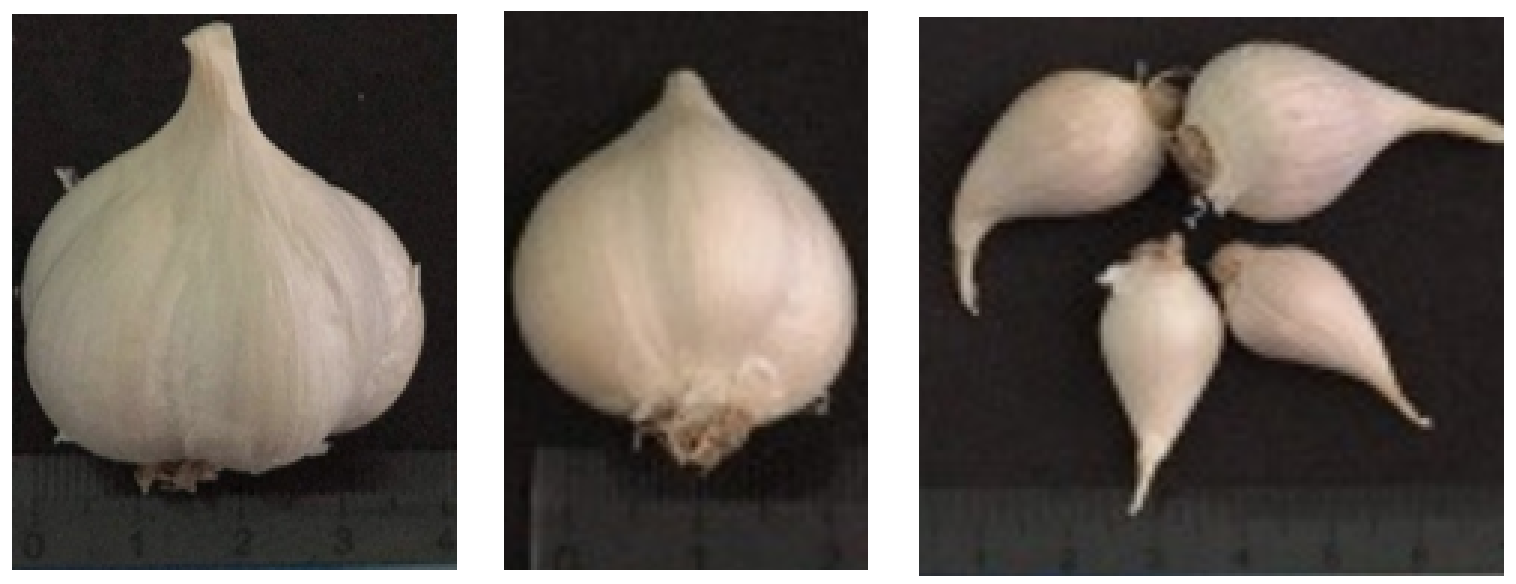

Hình 2. Củ tỏi loại 1 (trái), loại 2 (giữa) và tỏi 1 tép (phải).

\section{4. Ảnh hưởng của bốn mức phân đạm và ba mức kali đến hiệu quả kinh tế của cây tỏi}

Kết quả Bảng 6: khi bón $200 \mathrm{~kg} \mathrm{~N} /$ ha kết hợp với $120 \mathrm{~kg} \mathrm{~K} \mathrm{~K}_{2} \mathrm{O} / \mathrm{ha}$ có tổng thu cao nhất là 547.790 .000 đồng/ha/vụ do có tổng tỷ lệ củ tỏi loại 1 và loại 2 là 99,3\%, đạt lợi nhuận cao nhất là 373.665.800 đồng/ha/vụ và có tỷ suất lợi nhuận cao nhất là 2,15. Khi bón kết hợp $300 \mathrm{~kg}$ $\mathrm{N} / \mathrm{ha}+150 \mathrm{~kg} \mathrm{~K} 2 \mathrm{O} /$ ha cho lợi nhuận thấp nhất (243.249.200 đồng/ha/vụ) do chi phí đầu tư phân bón cao nhất.

\section{Kết Luận}

Trong điều kiện đất cát tại Ninh Thuận, bón kết hợp $200 \mathrm{~kg} \mathrm{~N}$ với $120 \mathrm{~K}_{2} \mathrm{O} /$ ha trên nền phân 20 tấn phân bò và $80 \mathrm{~kg} \mathrm{P} \mathrm{P}_{2} \mathrm{O}_{5} / \mathrm{ha}$, sẽ cho chiều cao cây tỏi đạt $58,2 \mathrm{~cm} /$ cây và 8,7 lá/cây ở 75 ngày sau trồng; giúp cây tỏi đạt năng suất lí thuyết là 15,87 tấn/ha, năng suất thương phẩm là 13,42 tấn/ha; đường kính củ tỏi lớn nhất $(3,5$ $\mathrm{cm})$ và có 17,1 tép/củ; tỷ lệ củ loại 1 đạt $45,5 \%$, loại 2 là $53,8 \%$ và củ 1 tép là $0,7 \%$; đạt lợi nhuận 373.665.800 đồng/ha/vụ và tỷ suất lợi nhuận cao nhất là 2,15 .

\section{Tài Liệu Tham Khảo (References)}

Gomez, K. A., \& Gomez, A. A. (1984). Statistical procedures for agricultural research. New Jersey, USA: John Wiley \& Sons.
Minard, H. R. G. (1978). Effect of clove size, spacing, fertilizers and lime on yield and nutrient contents of the garlic (Allium sativum). New Zealand Journal of Experimental Agriculture 6(2), 139-143.

Nguyen, B. L., Truong, V. L., Vo, T. M. H., Le, T. H. \& Le, T. T. (2011). Plant physiology Textbook. Thai Nguyen University of Education, Thai Nguyen, Vietnam.

Nguyen, L. M. V. (2012). Effect of manure, N, P and $K$ on the growth and yield of garlic (Allium sativum L.) planting on sandy soil in Phan Rang - Thap Cham city, Ninh Thuan province (Unpublished master's thesis). Nong Lam University, Ho Chi Minh City, Vietnam.

NTSD (Ninh Thuan Statistic Department). (2017). Cultivation, yield and production of garlic crop in Ninh Thuan province 2016. Ninh Thuan Statistic Department, Ninh Thuan, Vietnam.

Sebnie, W., Merse, M., Gebrehana, G., \& Tesfaye, F. (2018). Response of garlic (Allium sativum L.) to nitrogen and phosphorus under irrigation in Lasta district of Amhara Region, Ethiopia. Cogent Food and Agriculture 4(1), 1532862.

Tran, T. H. T. (2015). Effect of $N$ and $S$ on the yield of garlic (Allium sativum L.) in sandy - clay soil in Ninh Hai district, Ninh Thuan province (Unpublished master's thesis). Nong Lam University, Ho Chi Minh City, Vietnam. 